\title{
Uma cidade, o garimpo de esmeraldas e a decadência: o caso de Santa Terezinha de Goiás
}

\author{
Fudio Matsuura \\ Antônio Pasqualetto \\ Ubirajara de Lima Ferreira
}

\begin{abstract}
Resumo
Foi a mineração que deu origem a cidades na região norte de Goiás. Neste artigo se objetiva avaliar se o processo de ocupação do território deparou com problemas sociais, econômicos e institucionais, e analisar as mudanças ocorridas na região com a descoberta das minas de esmeraldas. A metodologia envolveu pesquisa de campo com a aplicação de questionários a 116 pessoas para verificar como a população percebia historicamente a territorialidade e o desenvolvimento trazido (ou não) pelo garimpo. Consideraram-se, para tanto, três etapas: a cidade antes do garimpo, a cidade com o garimpo e a cidade e a decadência do garimpo. Os resultados evidenciaram que a exploração de esmeraldas causou impactos socioeconômicos na infraestrutura da cidade, levando a um rápido desenvolvimento econômico local, posteriormente desarticulado com a decadência dessa atividade, e então caminhando para um cenário de degradação e abandono. A cidade de Santa Terezinha de Goiás segue a lógica das cidades mineradoras do Brasil, marcadas por desenvolvimento rápido e não planejado, população flutuante, agressão ao meio ambiente e esvaziamento urbano e regional.
\end{abstract}

Palavras-chave | Cidade; decadência; desenvolvimento urbano e regional; garimpo; Santa Terezinha de Goiás.

Classificação JEL | L72 N56 O18

A city, the mining of esmeralds and decay: the case of Santa Terezinha de Goiás

\begin{abstract}
Mining gave rise to cities in the northern region of Goiás. In this sense, the objective was to assess whether the process of occupation of the territory faced social, economic and institutional problems and to analyse the changes that occurred in the region with the discovery of the emerald mines. To this end, the methodology involved field research with the proposal of questionnaires to 116 people to observe how the population of this location historically
\end{abstract}


perceived the territoriality and the development brought about or not by the mining, considering three temporal stages: The city before mining, local development, based on gold mining, and the city with the decay of gold mining. The results showed that the exploitation of emeralds caused socioeconomic impacts on the infrastructure of this city, establishing rapid local and economic development and subsequently dismantled with the decay of this activity, moving from the apparent development to the scenario of degradation and abandonment to which this region was relegated. The city of Santa Terezinha de Goiás follows the logic of mining cities in Brazil, marked by rapid development, without planning, fluctuating population, aggression to the environment and an empty city.

Keywords | City; decay; mining; urban and regional development; Santa Terezinha de Goiás.

\section{JEL Classification | L72 N56 O18}

\section{Una ciudad, la minería de esmeraldas y la decadencia: el caso de Santa Terezinha de Goiás}

\section{Resumen}

La minería dio origen a ciudades en la región norte de Goiás. El objetivo en este artículo es evaluar si el proceso de ocupación del territorio enfrentó problemas sociales, económicos e institucionales, y analizar los cambios ocurridos en la región con el descubrimiento de las minas de esmeraldas. La metodología incluyó una investigación de campo con la aplicación de cuestionarios a 116 personas para observar cómo la población históricamente percibía la territorialidad y el desarrollo provocado (o no) por la minería. Se consideraron, para eso, tres etapas: la ciudad antes de la minería, la ciudad con la minería, y la ciudad y la decadencia de la minería. Los resultados mostraron que la explotación de las esmeraldas causó impactos socioeconómicos en la infraestructura de la ciudad, estableciendo un rápido desarrollo económico local, posteriormente desmantelado con la decadencia de esta actividad, pasando entonces para un escenario de degradación y abandono. La ciudad de Santa Terezinha de Goiás sigue la lógica de las ciudades mineras en Brasil, marcada por un rápido desarrollo, sin planificación, población fluctuante, agresión al medio ambiente y vaciamiento urbano y regional.

Palabras clave | Ciudad; decadencia; desarrollo urbano y regional; minería; Santa Terezinha de Goiás.

Clasificación JEL | L72 N56 O18

\section{Introdução}

O ser humano necessita de território e espaço, bem como criar vínculos com o ambiente. Neste sentido, indaga-se se o desenvolvimento local em Santa Terezinha de Goiás, na década de 1980, época áurea da exploração do garimpo de esmeralda, segue a lógica das cidades mineradoras no Brasil. 
Para compreender um objeto de estudo - especialmente em ciências humanas e áreas afins -, este deve ser situado historicamente, em suas relações reais e nas mediações por ele estabelecidas. No caso em questão, deve ser situado no âmbito do processo de territorialização e desterritorialização no qual se originou, não de forma autônoma, mas entremeado e inserido no contexto da exploração de esmeraldas no Brasil, ressaltando a singularidade e os significados assumidos.

A expressão desenvolvimento regional é contemplada em diversas línguas. Com efeito, em jornais especializados, publicados em inglês, encontra-se regional development, em periódicos especializados publicados em língua alemã, encontra-se, com frequência, o emprego do termo regionalentwicklung; também em periódicos especializados publicados em língua francesa é comum encontrar développement regional; e em periódicos especializados publicados em espanhol observa-se bastante a utilização da expressão desarrollo regional (THEIS, 2019).

Para Oliveira, Silva e Lovato (2014), pode-se definir desenvolvimento regional como sendo o conjunto de diversas dinâmicas que se relacionam (social, econômica, política e cultural), atuantes em um território demarcado por características próprias e que induzem a mudanças qualitativas em sua estrutura.

Ressalta-se a relevância de estudos voltados para o desenvolvimento regional, em especial o desenvolvimento local, a territorialidade e a desterritorialidade, considerando a dimensão espacial dos fenômenos socioeconômicos nas diferentes ciências sociais, e que buscam explicitar o dinamismo e/ou o declínio de certas regiões ou lugares com base nas configurações do espaço e nas ações empreendidas por atores e instituições.

Assim sendo, um espaço físico é considerado "lugar" quando as pessoas dão significado a esse espaço; portanto, não basta estar delimitado. Em seu livro "A Percepção de Lugar", Lineu Castello define o que se pode chamar de "origem" do lugar da seguinte forma: "[...] lugar é um espaço qualificado [...] que se torna percebido pela população por motivar experiências humanas a partir da apreensão de estímulos ambientais" (CASTELLO, 2007, p. 14). O referido autor ressalta ainda que "[...] são as pessoas e o uso que essas pessoas fazem do ambiente construído o quê, com o tempo, pode conferir o status diferenciado que os lugares urbanos desfrutam nas cidades" (CASTELLO, 2007, p. 21)).

Tendo em visa a compreensão das mediações apresentadas pelo objeto de estudo, o presente artigo objetiva avaliar o desenvolvimento regional local ocorrido no município de Santa Terezinha de Goiás, bem como a relação entre mobilidade espacial e territorialidade com a descoberta das minas de esmeralda. Para tanto, fazse necessário verificar se o processo de ocupação do território enfrentou problemas sociais, econômicos e institucionais, e analisar, sob as perspectivas histórica e dos habitantes, as mudanças ocorridas na região com a descoberta das minas de esmeraldas 
Para a consecução desse objetivo, procedeu-se a uma pesquisa de campo, com aplicação de questionários, a fim de compreender como a população dessa localidade percebe historicamente a territorialidade no desenvolvimento influenciado pelo garimpo.

\section{Cidades mineradoras}

Segundo Silva (2013), o território envolve mais que questões espaciais, visto que é perpassado por relações sociais, que também são produtos e produtoras de novas configurações territoriais e definem práticas reveladoras de interesses diversificados, partindo de diferentes atores sociais. Estes, no território, expressam vontades e anseios; enfim, práticas sociais, culturais, econômicas e políticas em seus contextos históricos.

No Brasil, a exploração de minérios ainda tem expressiva representatividade na economia nacional (BRITO, 2012). No início da segunda década do século XXI, a atividade mineradora correspondia a cerca de 3\% a 4\% do Produto Interno Bruto (PIB), empregando diretamente centenas de milhares de pessoas, além de outras centenas de milhares ligadas indiretamente ao setor (VIEIRA, 2011).

Essa atividade, no entanto, apresenta-se de forma contraditória: por um lado traz prosperidade aos municípios, gerando desenvolvimento local; por outro, caracteriza-se como atividade incerta, de fluxo sazonal, acarretando consequências negativas ao local onde estão inseridas.

O caráter temporal das minas de exploração seja talvez o maior problema, uma vez que essas possuem tempo limite para exploração. Neste sentido, determinada região onde há minas vive, inicialmente, um período áureo; depois, vê-se esvaziada, o que gera desemprego e subutilização da infraestrutura implantada, impactando de forma negativa a economia local (VIEIRA, 2011).

Os trabalhadores dos garimpos — os garimpeiros — possuem em comum a frequente mobilidade espacial; são destituídos de vínculos estáveis com a terra e deslocam-se permanentemente na busca de oportunidades para a sobrevivência e a ascensão social (VIEIRA, 2011). Macedo (2000, p. 28) afirma que “[...] o homem se faz garimpeiro porque é uma profissão fascinante, que embriaga com a ilusão de torná-lo rico da noite para o dia”.

Muitos garimpos - como observado na região da Amazônia - contam com trabalhadores que abandonaram a atividade agrícola ou que mantêm alternância entre essa atividade e a garimpagem. Eles transitam periodicamente entre uma e outra, em um ritmo cíclico que acompanha a sazonalidade de ambas (SOUZA, 1986). 
Em outras regiões brasileiras, diferentemente do que ocorreu na Amazônia, os garimpos caminharam para maior estabilização social e espacial, o que se deu mediante participação dos garimpeiros vindos de outras regiões, bem como da população local (SOUZA, 1986).

As intervenções territoriais dos empreendimentos na ocupação do cerrado, por exemplo, intensificaram os conflitos socioambientais e impactaram a organização do trabalho e dos espaços da existência dos povos cerradeiros (PELÁ; MENDONÇA, 2010), principalmente em Goiás. Quanto à mineração nos territórios desse estado, verifica-se a apropriação do subsolo pelo capital transnacional (GONÇALVES; MENDONÇA, 2015).

Segundo Ferreira (2012), nesse contexto devem ser observadas também as poluições sonora, do ar e da água, que afetam diretamente as comunidades onde essas empresas se fixaram, como a de Macaúba, localizada no município de Catalão, também no estado de Goiás.

Conforme Póvoa-Neto (1997), são exemplos de garimpos consolidados na região do cerrado: os de diamante, no Vale do Jequitinhonha mineiro, na Chapada Diamantina baiana e no Alto Vale do Araguaia goiano e mato-grossense; os de ouro, em Poconé (Mato Grosso), Crixás e Minaçu (Goiás); os de esmeralda, em Campos Verdes (Goiás), Nova Era (Minas Gerais) e Carnaíba (Bahia). Afirma ainda o autor que os garimpos consolidados se iniciaram nos anos 1980 e tiveram sua retomada em novas bases.

A fim de corroborar sua análise Póvoa-Neto (1997) afirma que, em muitos garimpos, currutelas evoluíram e se tornaram núcleos consolidados, alcançando, por vezes, o status de novos municípios. Essa é a realidade do garimpo de esmeraldas de Campos Verdes. Antes, essa cidade não era emancipada, pertencendo, assim, à Santa Terezinha de Goiás. O "garimpo", como era chamado, emancipou-se, o que deu origem ao município de Campos Verdes.

Importa destacar que nos garimpos ocorre um processo de desenvolvimento desordenado: no momento áureo das minas, pessoas atraídas pela possibilidade de enriquecimento chegam de várias partes do país. Essa população crescente e sem emprego provoca, na área do garimpo, uma ocupação irregular, com residências precárias e, muitas vezes, sem os serviços de água e esgoto, dando origem a áreas de risco social.

Em seus estudos, Vieira (2011) afirma que as cidades ocupadas pela atividade mineradora crescem sem um plano global e não têm como prever os problemas, passando a administração local apenas a tentar saná-los. Desse modo, cabe ao município o desafio de criar estratégias para o enfrentamento à nova realidade, caracterizada por uma população flutuante, de alta rotatividade e pela falta de vínculo local entre as pessoas. 
Outra característica das cidades mineradoras é que a maioria não está preparada para enfrentar os danos ambientais. Boa parte da atividade mineradora não possui planejamento, o que provoca danos ao meio ambiente. Dessa forma, é no decorrer do processo de extração mineral que alternativas são buscadas para o enfrentamento à problemática ambiental. A isso soma-se a poluição dos córregos e do solo, causada pela lavagem do minério (BRITO, 2012).

\section{Metodologia}

\section{Caracterização da área de estudo}

O objeto de estudo foi a cidade de Santa Terezinha de Goiás (Figura 1), localizada na mesorregião do Norte Goiano, a $300 \mathrm{~km}$ da capital do estado, Goiânia. O município é o quinto maior em extensão de sua microrregião (IBGE, 2018). Assim, com base em um recorte temporal, foram analisadas as décadas de 1980, período áureo do garimpo, e a de 1990, quando ocorreu a crise e o processo de desterritorialização.

Figura 1 - Mapas da mesorregião do Norte Goiano e do município de Santa Terezinha de Goiás

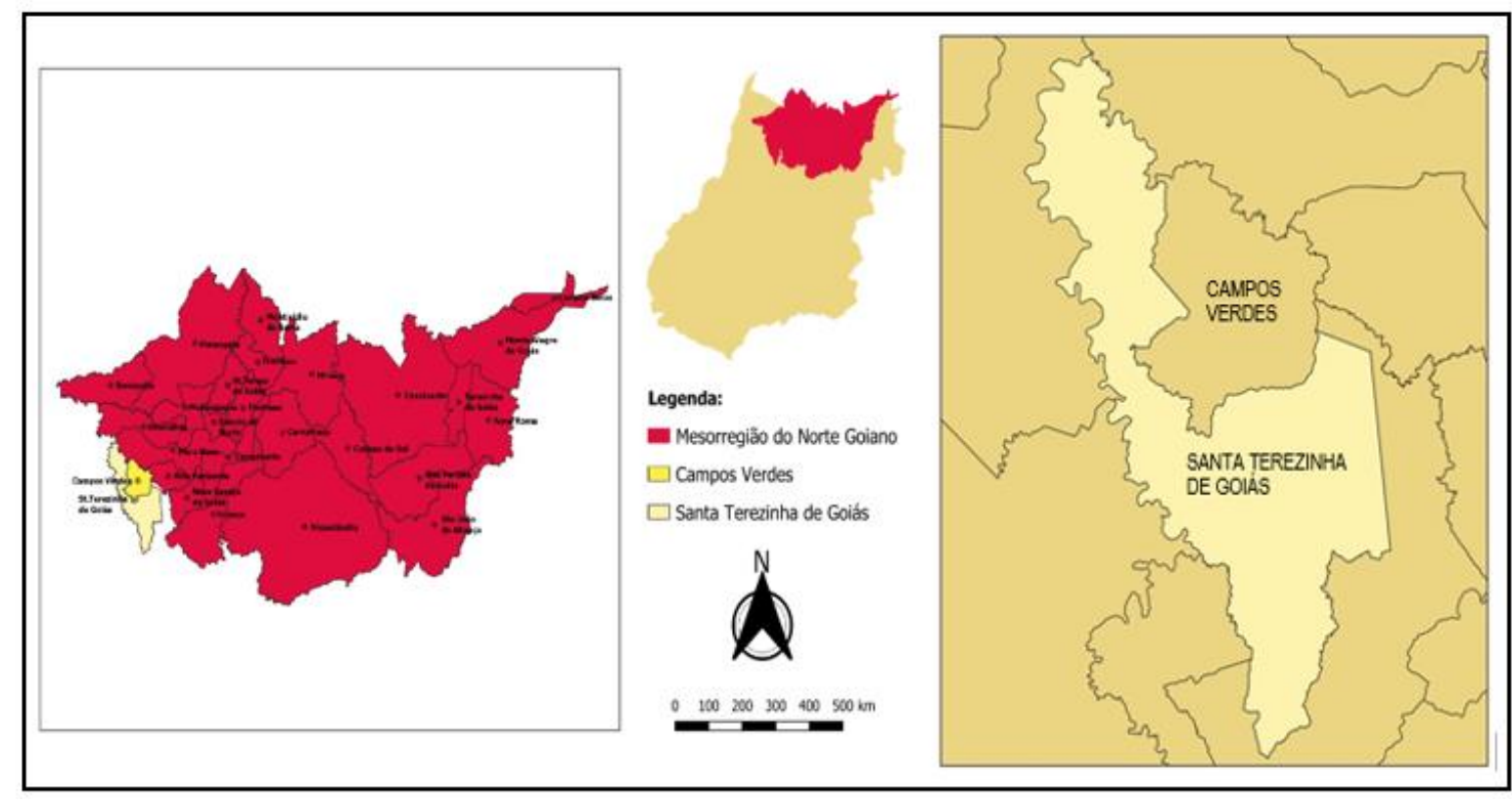

Fonte: SIGEAP; IBGE (2019); elaboração própria. 


\section{Universo e amostra da pesquisa}

A pesquisa ocorreu no ano de 2019, em Santa Terezinha de Goiás. Observou-se, para a definição da amostra da pesquisa, o número de habitantes do município, conforme estimativa do Instituto Brasileiro de Geografia e Estatística (IBGE, 2018). Desse modo, considerou-se 1,3\% habitantes, totalizando 116 pessoas selecionadas para a entrevista dentre as que vivenciaram a realidade da mineração.

\section{Instrumento e variáveis de pesquisa}

Para proceder à investigação, a coleta de dados foi feita por meio de aplicação de um questionário estruturado, em consonância com os métodos propostos. Para a aplicação, considerou-se o período desde a criação do povoado de Santa Terezinha de Goiás até a emancipação do município, entre os anos de 1950 e 1960, chegando à década de 1990, com a decadência do garimpo e os impactos locais.

Por fim, cada dimensão se completou, subdividindo-se em variáveis que orientaram a elaboração do questionário de pesquisa e a aplicação para melhor responder aos objetivos da investigação, bem como a pertinência das técnicas de coleta de dados relativas à problemática apontada, a saber:

- Dimensão 1 - A cidade antes do garimpo;

- Dimensão 2 - Desenvolvimento local: a cidade com o garimpo;

- Dimensão 3 - A cidade e a decadência do garimpo.

Os dados analisados estão representados pelas Figuras 2, 3 e 4. Os resultados encontrados foram confrontados com a literatura especializada.

\section{Resultados e discussões}

Em Santa Terezinha de Goiás, os questionários foram aplicados a 116 pessoas, sendo 73 trabalhadores diversos; 24 comerciantes; 1 garimpeiro; 11 funcionários públicos; e 7 sujeitos que se enquadram na categoria "outros".

\section{Dimensão 1 - A cidade antes do garimpo}

Para 45,69\% dos entrevistados, a população existente em Santa Terezinha de Goiás era menor que 10.000 habitantes antes da descoberta de esmeraldas; para 32,76\%, representava mais de 10.000. Em 1980, a população estimada no município era de 10.964 habitantes (IBGE, 2018). Na década de 1970, Santa Terezinha de Goiás era simplesmente mais um município do estado sem grande expressividade, com economia voltada para a agropecuária, apresentando um pequeno e modesto 
comércio local. Ressalta-se que o município foi fundado em 23 de outubro de 1963. $\mathrm{Na}$ Figura 2, encontram-se os dados da pesquisa referentes à Dimensão 1 (a cidade antes do garimpo).

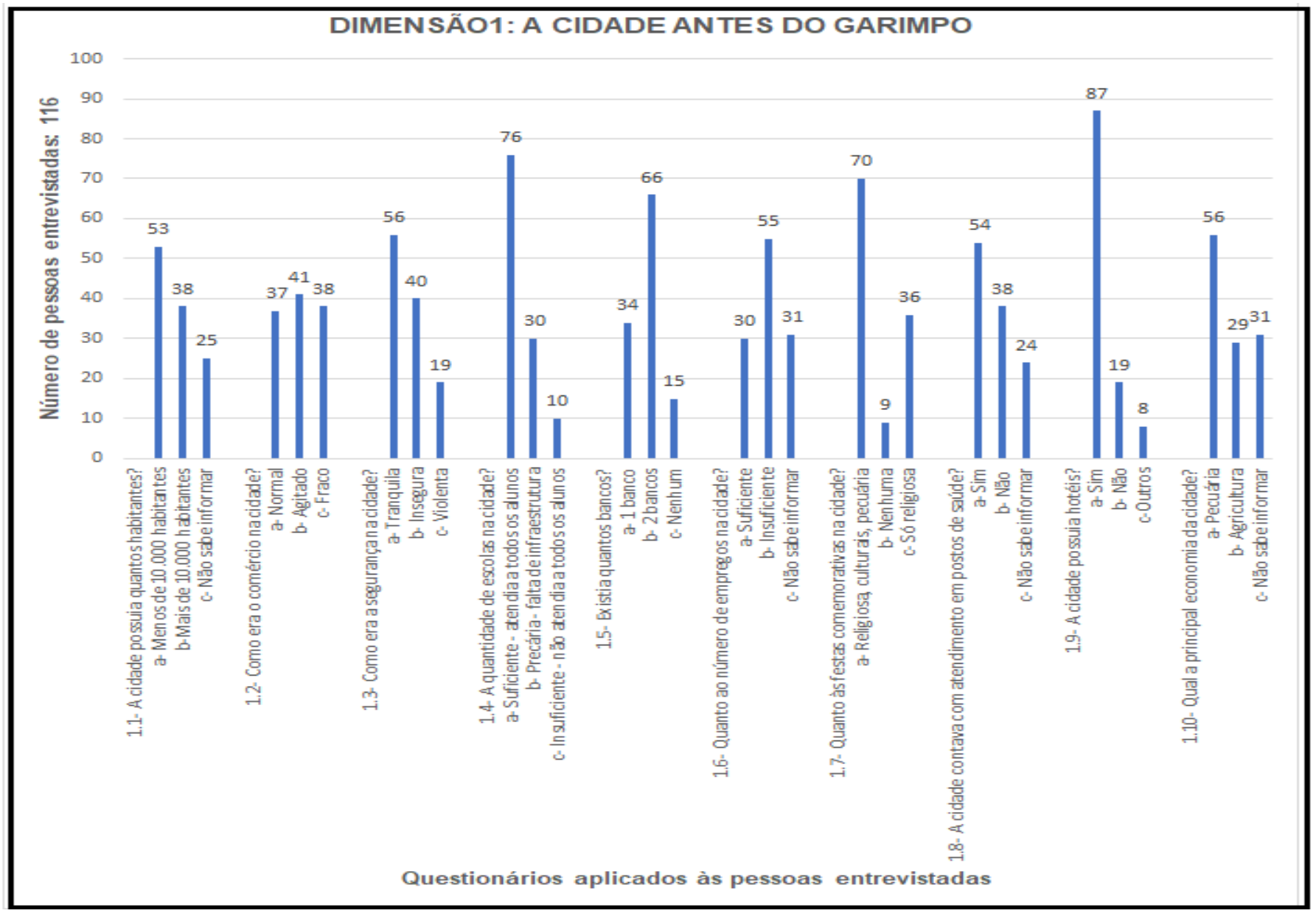

Figura 2 - Dimensão 1 'a cidade antes do garimpo'

Fonte: Elaboração própria.

À época, para 31,9\%, o movimento do comércio na cidade era normal; para 35,34\%, era agitado; e para 32,76\%, fraco. Esse equilíbrio entre os dados levantados evidencia que, na época, não existiam parâmetros diferenciados na economia que determinassem essas tendências.

Com relação à segurança, 48,28\% dos entrevistados pontuaram que a cidade aparentava ser tranquila. Quanto às escolas, $65,52 \%$ relataram que a quantidade de estabelecimentos de ensino era suficiente. Com relação aos bancos, 56,9\% dos entrevistados responderam que 2 (duas) unidades ofereciam esse tipo de serviço. Como a economia da cidade estava voltada para a agropecuária e o modesto comércio local, os bancos atendiam satisfatoriamente a economia local. 
No que se refere à quantidade de empregos, os índices mostraram-se mais preocupantes. Para 47,41\%, era insuficiente, dada a especificidade de atividade desenvolvida; não existiam oportunidades de empregos que viessem atender a toda a necessidade da população. O observatório do trabalho descreve tal fenômeno (IFG, 2013).

Dentre as festas comemorativas, religiosas, culturais e vinculadas à pecuária, $60,34 \%$ afirmaram recordar que fiéis católicos do município de Santa Terezinha de Goiás se deslocavam para outras duas cidades para participarem de festas religiosas: Guarinos (Festa do Divino Pai Eterno) e Muquém (Festa de Nossa Senhora da Abadia). O tradicional evento folclórico das Festas Juninas, com alusão a São João, Santo Antônio e São Paulo, ocorria, na cidade, na segunda quinzena do mês de junho (BRITO, 2012), justificando, dessa forma, a presença de hotéis.

Com relação ao atendimento em postos de saúde, 45,55\% dos entrevistados responderam que o município de Santa Terezinha de Goiás possuía esse tipo de serviço, evidenciando, assim, boa estrutura na área da saúde. Ademais, o atendimento prestado à população era de qualidade.

No tocante à pecuária, motor da economia no município antes da chegada do garimpo, 48,28\% das pessoas entrevistas ratificaram que essa era a principal atividade econômica de Santa Terezinha de Goiás, assim como muitos outros municípios goianos, que, até hoje, concentram suas atividades na agricultura e na pecuária.

Observa-se que o território de Santa Terezinha de Goiás é percebido como fonte de recursos, estando inserido no confronto entre classes sociais e na relação capitaltrabalho. Haesbaert (2004) aponta outra dimensão, a natural, que concebe o território com base nas relações entre sociedade e meio ambiente, principalmente quanto ao comportamento dos seres humanos no espaço físico.

Para Raffestin (1993), o território não é nada mais do que o produto dos atores sociais, pois são estes que produzem aquele, partindo da realidade inicial dada, que é o espaço. Há, portanto, um "processo" do território quando se manifestam todas as espécies de relações de poder. Neste sentido, esse processo envolve as ações dos atores sociais, distribuídas em redes interligadas em pontos ou nós.

Os dados levantados apontam para questões pertinentes ao estudo. No que se refere ao desenvolvimento local, percebe-se que, ao associá-lo à qualidade de vida e à prestação de serviços, como saúde e educação, a comunidade mostra-se, em sua maioria, satisfeita, mesmo antes da mineração. Apenas dois itens, emprego e comércio, apresentaram baixos índices. A maioria pontuou a oferta de empregos como insuficiente, tendo, portanto, dificuldade em perceber o comércio como atividade relevante.

Neste sentido, a ideia de desenvolvimento associada ao uso econômico do território urbano mostrou-se inconsistente para aquele período. O seu uso era mais cultural, 
o que representa a estruturação de um sistema territorial afastado da cidade e vinculado à área rural, posto que as atividades econômicas mais comuns eram a pecuária e a agricultura.

\section{Dimensão 2 - Desenvolvimento local: a cidade com o garimpo}

Acerca da leitura da realidade do município após a descoberta da área de mineração, alguns dados foram levantados, como mostra a Figura 3, que apresenta as respostas à Dimensão 2 (desenvolvimento local: a cidade com o garimpo).

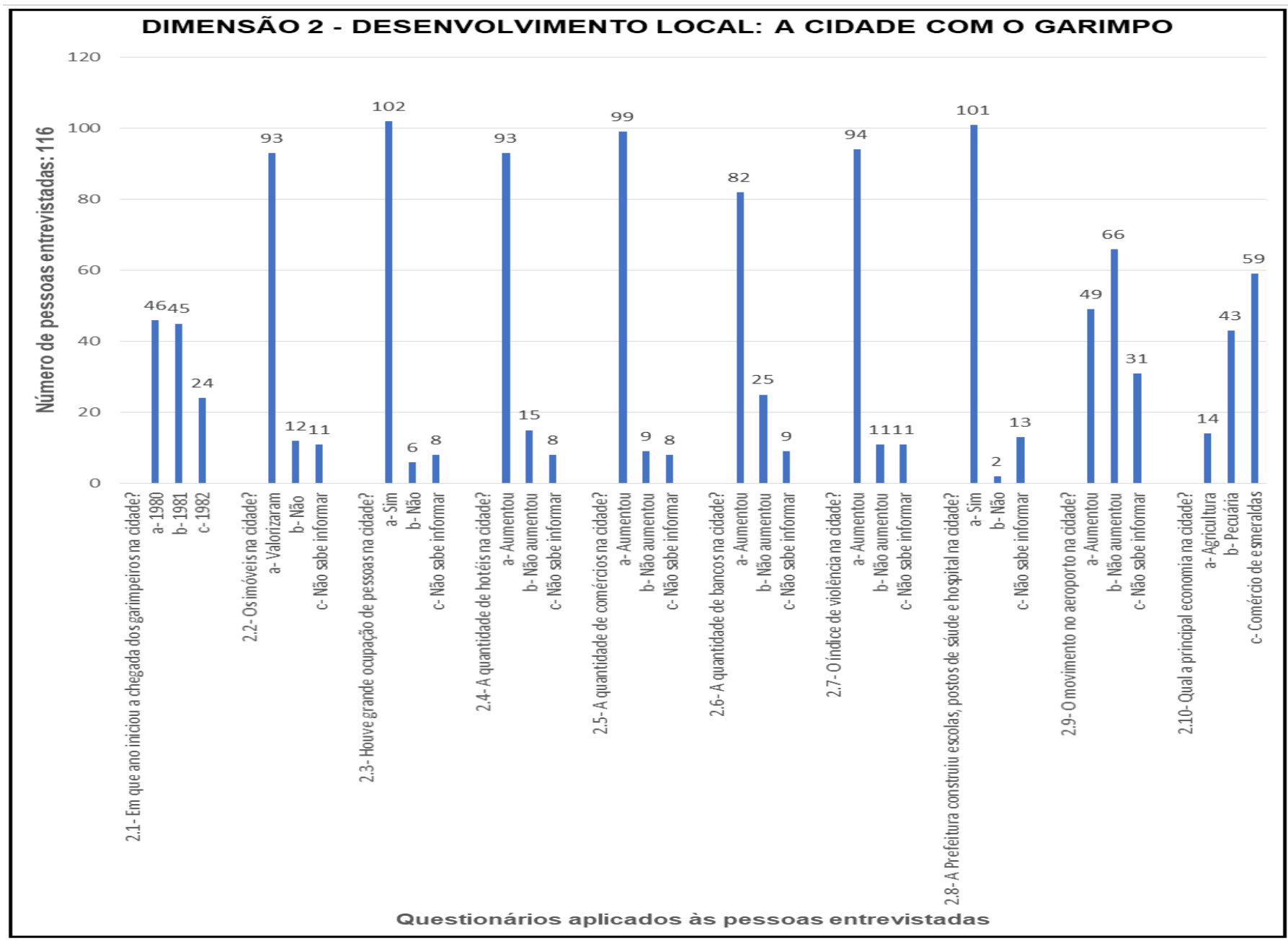

Figura 3 - Dimensão 2 'desenvolvimento local: a cidade com o garimpo'

Fonte: Elaboração própria.

Conforme observado, para 39,66\% dos entrevistados, os garimpeiros chegaram a partir de 1980; para 38,79\%, eles chegaram em meados de 1981; e para 20,69\%, em 1982. A despeito do ano da chegada dos primeiros garimpeiros na região, os dados 
levantados confirmam a ideia de "invasão" da cidade de Santa Terezinha de Goiás no início da década de 1980 por esses trabalhadores.

Conforme Haesbaert (2014, p. 59), a distinção dos territórios se dá “[...] de acordo com aqueles que o constroem, sejam eles indivíduos, grupos sociais/culturais, o Estado, empresas e instituições como a Igreja". O objetivo de controle social que se dá em ações de territorializações varia de acordo com a sociedade e a cultura (renda, idade, gênero etc.).

Para 80,17\%, com a chegada de pessoas no garimpo, houve valorização dos imóveis. Esses índices foram ratificados pela percepção dos entrevistados quanto ao grande número de hotéis na cidade durante o período do garimpo. Na esteira desses acontecimentos, $87,93 \%$ afirmaram que a cidade foi ocupada. Observa-se, portanto, um superpovoamento em Santa Terezinha de Goiás, chegando o município a ter, no período áureo do garimpo, uma população de mais de 25 mil habitantes, tornando-se o maior produtor de esmeraldas do mundo, o que provocou verdadeira efervescência econômica, bem como a ampliação do comércio de abastecimento de alimentos, roupas e instrumentos utilizados no garimpo (BRITO, 2012).

Durante esse período, houve alteração na realidade econômica do município, sendo que o comércio das esmeraldas passou a ser a principal atividade em detrimento da pecuária. Neste sentido, o crescimento do município ocorreu com a oferta de serviços das mais diferentes áreas (agências bancárias, construção de escolas, postos de saúde e hospitais, aumento de movimento no aeroporto da cidade, entre outras).

No caso das atividades bancárias, o aumento do número de agências foi percebido por 70,69\% dos entrevistados. Na cidade, foram instaladas agências do Banco do Brasil, da Caixa Econômica Federal, do Bradesco, do Bamerindus e do extinto Banco do Estado de Goiás (BEG), a fim de garantir serviços bancários aos cidadãos (SILVA, 2006). Com relação às escolas, postos de saúde e hospitais durante o período do garimpo, 87,07\% afirmaram que houve aumento no número desses estabelecimentos. Acerca do fluxo no aeroporto da cidade, $42,24 \%$ responderam que o movimento aumentou durante o período do garimpo. Como consequência do aumento número de pessoas circulando em Santa Terezinha de Goiás, os índices de violência cresceram, conforme declarado por $81,03 \%$. Importa mencionar que a criminalidade aumentou bastante à época, chegando a ponto de a Polícia proibir o consumo de bebida alcoólica e até a entrada de mulheres solteiras no Garimpo.

Em Santa Terezinha, um dos locais de maior violência era o prostíbulo, conhecido pelos moradores como Malvinas. Os garimpeiros deram esse nome ao prostíbulo em referência à Guerra das Malvinas, conflito entre a Grã-Bretanha e a Argentina na década de 1980, pelo fato de todas as noites saírem do local pessoas esfaqueadas, baleadas e até mesmo mortas. Esse prostíbulo teve, nos tempos áureos, aproximadamente 500 mulheres atuando como prostitutas (BRITO, 2012).

Os dados apresentados conduzem a reflexões importantes. Primeiro, o aumento da oferta de serviços, o que poderia significar melhoria da qualidade de vida, ratificando 
a noção de desenvolvimento. Todavia, o aumento da violência põe em dúvida essa primeira observação. Segundo a mudança da territorialização, ou seja, o garimpo trouxe mudança significativa na apropriação social sobre o território dessa localidade, o que provocou nova territorialidade, pois o uso social que se fez do espaço no decorrer do tempo alterou-se substancialmente. A esse aspecto soma-se a estruturação de um sistema territorial urbano, fato não observado pela população antes do garimpo e que se tornou perceptível a partir de então, visto que o comércio passou a ser a principal atividade econômica e transformou o território da cidade em meio de produção e produto dessa realidade.

\section{Dimensão 3 - A cidade e a decadência do garimpo}

A Figura 4 apresenta as respostas à Dimensão 3 (a cidade e a decadência do garimpo).

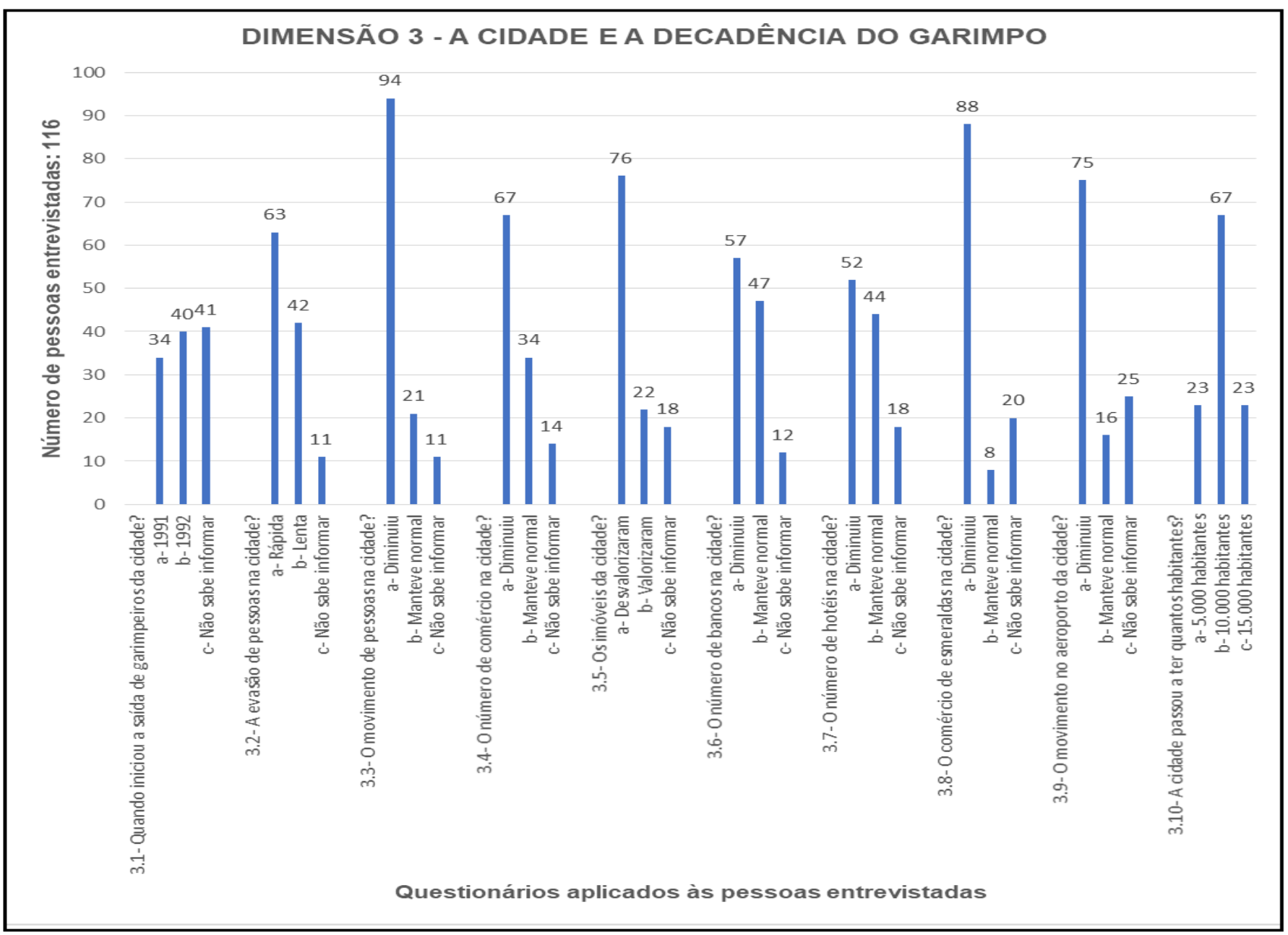

Figura 4 - Dimensão 3 'a cidade e a decadência do garimpo'

Fonte: Elaboração própria. 
Esse item mostra como a cidade foi da prosperidade à decadência, confirmando, no caso de Santa Terezinha de Goiás, algumas das características das cidades mineradoras: população flutuante, alta rotatividade e falta de vínculo local.

Com relação à saída dos garimpeiros, 29,31\% dos entrevistados afirmaram que isso ocorreu em 1991; para 34,48\%, em 1992. Importa destacar que, do total dos que responderam ao questionário, 54,31\% afirmaram que essa retirada ocorreu de forma rápida.

Dentre os entrevistados, 81,03\% afirmaram que após a saída dos garimpeiros o fluxo de pessoas reduziu na cidade; 57,76\% responderam que houve queda da população, voltando Santa Terezinha de Goiás a ter aproximadamente 10.000 habitantes, além de diminuição no número de estabelecimentos comerciais. Para $44,83 \%$, houve uma queda no número de hotéis após a decadência do garimpo.

Com a evasão dos garimpeiros, os imóveis desvalorizam-se, conforme $65,52 \%$ das respostas obtidas; $75,86 \%$ afirmaram que houve redução no comércio de esmeraldas. Esses dados são corroborados pela percepção de 64,66\% dos entrevistados, que confirmaram a diminuição do fluxo pessoas no aeroporto da cidade.

A Tabela 1 apresenta índices não satisfatórios com relação a empregados e desempregados em várias atividades econômicas no município, no período de 1998 a 2018.

Tabela 1 - Cadastro Geral de Empregados e Desempregados em Santa Terezinha de Goiás

\begin{tabular}{lccccccc}
\hline Atividade econômica & 1998 & 2000 & 2005 & 2010 & 2015 & 2017 & 2018 \\
\hline Administração pública & 2 & 0 & 0 & 0 & 0 & 0 & 0 \\
Extração mineral & 0 & 0 & 0 & 0 & 0 & -1 & 1 \\
Comércio & 11 & 11 & 7 & 38 & -28 & -5 & 28 \\
Construção civil & 0 & 1 & 1 & 2 & 15 & -8 & 13 \\
Indústria de transformação & -2 & -5 & -6 & 24 & -3 & 8 & 6 \\
Serviços & 8 & 9 & -2 & 18 & -7 & -21 & 21 \\
\hline
\end{tabular}

Fonte: Instituto Mauro Borges (IMB, 2018).

De acordo com a tabela apresentada, alguns aspectos devem ser observados. Primeiro, verifica-se a incompatibilidade entre a percepção social e os dados populacionais do IBGE, que apresentam um pico demográfico em 1991, com 16.522 habitantes, drasticamente reduzido nove anos depois para 12.015 habitantes. Segundo, percebe-se a reestruturação do uso do território, marcada pela desterritorialidade e pela desmontagem do sistema baseado no comércio de esmeraldas. 
É importante destacar ainda que, com a emancipação política de Campos Verdes, a cidade de Santa Terezinha de Goiás perdeu seu território de esmeraldas e, consequentemente, arrecadação e controle sobre o comércio desse minério.

A decadência do garimpo evidenciou as contradições das expectativas do desenvolvimento em Santa Terezinha de Goiás. Para Barquero (2002), o desenvolvimento econômico local poderia ser um processo de crescimento e mudança estrutural, tendo como base a transferência de recursos das atividades tradicionais para as modernas, bem como o aproveitamento das economias externas e de inovações, que elevam o bem-estar social.

A cidade sofreu com a ausência de uma organização em torno da mineração, e o poder público não deu respostas às demandas que foram surgindo. Isso possibilitou a entrada de atravessadores de outras localidades à área do garimpo, inclusive comprando as minas daqueles que não tinham como continuar com os serviços em função de inúmeros problemas, sendo o mais comum o financeiro.

Nada disso restou no território; restaram apenas as mazelas de uma atividade degradante à natureza e à sociedade. Quando as riquezas da mineração desaparecem, os sonhos também se perdem, e a pobreza impera, em contraposição a um futuro próspero.

\section{Considerações finais}

Neste estudo foram analisados cenários que marcaram a história da cidade de Santa Terezinha de Goiás, desde a sua fundação, passando pelo desenvolvimento local acelerado, provocado pela descoberta de minas de esmeraldas, chegando até a decadência advinda com a crise na extração de esmeraldas.

Importa ressaltar que a atividade mineradora possui características contraditórias: por um lado, traz prosperidade, gerando crescimento local rápido, com a exploração e a comercialização de minérios; por outro, apresenta-se como atividade incerta, devido ao limite de suas reservas minerais e à dificuldade de exploração em locais mais profundos e de difícil acesso, incidindo em alto investimentos para aquisição de maquinários possantes para perfurações mais profundas e com segurança.

Com relação à cidade de Santa Terezinha de Goiás, nota-se que esta viveu um período áureo e, em seguida, passou por um processo de esvaziamento rápido, que deixou apenas o desemprego e a subutilização da infraestrutura implantada, impactando de forma negativa a economia local.

Acerca dos garimpeiros, estes possuem em comum a frequente mobilidade espacial, estando destituídos de vínculos estáveis com a terra, deslocando-se permanentemente na busca de oportunidades para a sobrevivência e a ascensão 
social. O homem se faz garimpeiro porque é uma profissão fascinante, que o embriaga com a ilusão de torná-lo rico da noite para o dia.

Santa Terezinha de Goiás consiste em um exemplo da realidade das cidades mineradoras no Brasil: não possuía estrutura física e social para receber grande número de pessoas; o traçado e a estética acabaram por se perder; e os garimpeiros acomodavam-se em qualquer lugar.

Inicialmente, a atividade de extração de esmeraldas foi realizada por garimpeiros autônomos, que utilizavam técnicas rudes, na base da pá e da picareta. À medida que passou a ser conhecido, o garimpo chamou a atenção de firmas que empregavam tecnologias mais eficientes na extração desse minério. Essas, por sua vez, instalaram-se no local e passaram a ocupar o espaço do garimpeiro. Nesse caso, o uso de dragas causou, em poucos meses de operação, uma assustadora degradação ambiental, como também gerou desemprego. Isso fez com que vários garimpeiros saíssem da cidade em busca de novas fontes de renda, causando impactos negativos em toda a infraestrutura local.

Com a emancipação de Campos Verdes, em 1987, a cidade de Santa Terezinha de Goiás perdeu seu território de esmeraldas; consequentemente, a arrecadação e o controle econômico, vivendo a partir daquele momento um processo de decadência, esvaziamento e crise econômica e social.

\section{Fonte(s) de Financiamento}

Coordenação de Aperfeiçoamento de Pessoal de Nível Superior (CAPES) e Fundação de Amparo à Pesquisa do Estado de Goiás (FAPEG).

\section{Referências}

BARQUERO, A. V. Desenvolvimento endógeno em tempos de globalização. Porto Alegre: Ed. UFRGS, 2002.

BRITO, I. B. de. Políticas públicas de apoio às famílias impactadas pela crise mineradora em Santa Terezinha de Goiás. 2012. 79f. Dissertação (Mestrado em Desenvolvimento Regional) - Faculdades Alves Farias, Goiânia, 2012.

CASTELLO, L. A percepção do lugar. Porto Alegre: PROPAR; Ed. UFRGS, 2007.

FERREIRA, A. P. S O. Territórios em conflito: a comunidade Macaúba/Catalão (GO) e a territorialização da atividade mineradora. 2012. 88f. Dissertação 
(Mestrado em Geografia) - Programa de Pós-Graduação em Geografia, Universidade Federal de Goiás, Campus Catalão, 2012.

GONÇALVES, R. J. A. F.; MENDONÇA, M. R. Expansão dos grandes empreendimentos da mineração e territórios em disputa no cerrado goiano (Goiás/Brasil). Sociedade e Território, vol. 27, n. 2, p. 206-228, set. 2015.

HAESBAERT, R. O mito da desterritorialização: do fim dos territórios à multiterritorialidade. Rio de Janeiro: Bertrand Brasil, 2004.

HAESBAERT, R. Viver no limite: território e multi-transterritorialidade em tempos de insegurança e contenção. Rio de Janeiro: Bertrand Brasil, 2014.

IBGE. Dados estatísticos 2018. Rio de Janeiro: Instituto Brasileiro de Geografia e Estatística, s.d. Disponível em:

https://cidades.ibge.gov.br/brasil/go/santaterezinhadegoias/panorama. Acesso em: 22 jan. 2021.

IFG. Estudos Microrregionais. Goiânia: Observatório do Mundo do Trabalho/ Instituto Federal de Educação, Ciência e Tecnologia de Goiás, 2013.

IMB. Santa Terezinha de Goiás. Goiânia: Instituto Mauro Borges, 2018. Disponível em: www.imb.go.gov.com.br/estatisticasmunicipais/santaterezinhadegoias. Acesso em: 19 jan. 2021.

MACEDO, M. Os garimpos de diamante do Araguaia: Baliza 1922-1960. Goiânia: UCG, 2000.

OLIVEIRA, A. G.; SILVA, C. L.; LOVATO, E. L. Desenvolvimento local: conceitos e metodologias (políticas públicas de desenvolvimento rural e urbano). Revista Orbis Latina, vol. 4, n. 1, p. 110-123, jan./dez. 2014.

PELÁ, M.; MENDONÇA, M. R. Cerrado goiano: encruzilhadas de tempos e territórios em disputa. In: PELÁ, M.; CASTILHO, D. (Org.). Cerrados: perspectivas e olhares. Goiânia: Vieira, 2010.

PÓVOA-NETO, H. Migrantes, garimpeiros e seu "lugar" no território nacional: itinerância e mobilidade espacial do trabalho. GEO/UERJ, n. 2, p. 43-49, dez. 1997. Disponível em: http://www.epublicacoes.uerj.br/index.php/geouerj/article/view/21761. Acesso em: 10 jan. 2021. 
RAFFESTIN, C. Por uma geografia do poder. São Paulo: Ática, 1993.

SILVA, J. M. P. Uso do território e impactos socioambientais da atividade minerometalúrgica nas cidades de Parauapebas e Canaã dos Carajás no estado do Pará, Região Norte do Brasil. 14 EGAL: Encontro de Geógrafos da América Latina. Anais... Peru, 2013.

SILVA, S. A. de F. Campos Verdes: memória, história e saberes. 2006. 125f. Dissertação (Mestrado em Gestão do Patrimônio Cultural) - Universidade Católica de Goiás, Goiânia, 2006.

SOUZA, L. M. Desclassificados do ouro. 2 ed. Rio de Janeiro: Graal, 1986.

THEIS, I. M. O que é desenvolvimento regional? Uma aproximação a partir da realidade brasileira. Redes, vol. 24, n. 3, p. 334-360, set./dez. 2019.

VIEIRA, C. Cidades mineradoras. Belo Horizonte: Revista do IETEC, 2011. 
Data de submissão: 13/02/2020

Data de aprovação: 10/09/2020

Revisão: Daniela Matthes (português), Anderson de Miranda Gomes (inglês) e Yanet María Reimondo Barrios (espanhol).

Fudio Matsuura

Instituto Federal de Educação Ciência e Tecnologia de Goiás

Rua 75, 46 - Centro

74055-110 Goiânia/GO, Brasil

Orcid: http://orcid.org/0000-0002-0467-6871

E-mail: fudio.matsuura@gmail.com

\section{Antônio Pasqualetto}

Mestrado em Desenvolvimento e Planejamento Territorial / Pontifícia Universidade Católica de Goiás

Avenida Universitária, 1440 - Setor Universitário

74605-010 Goiânia/GO, Brasil

Orcid: http://orcid.org/0000-0002-8639-6725

E-mail: profpasqualetto@gmail.com

\section{Ubirajara de Lima Ferreira}

Bacharel em Direito

Avenida Deputado Jamel Cecílio, 2690 - Sala 2401 - Jardim Goiás

74810-100 Goiânia/GO, Brasil

Orcid: https://orcid.org/0000-0001-5822-8620

E-mail: Bira237@terra.com.br 